\title{
GeneChip analysis of resistant Mycobacterium tuberculosis with previously treated tuberculosis in Changchun
}

\author{
Ming-Jin Zhang ${ }^{1,2}$, Wen-Zhi Ren ${ }^{1}$, Xue-Juan Sun², Yang Liu², Ke-Wei Liu², Zhong-Hao Ji', Wei Gao ${ }^{1 *}$
} and Bao Yuan ${ }^{1 *}$ (D)

\begin{abstract}
Background: With the widespread use of rifampicin and isoniazid, bacterial resistance has become a growing problem. Additionally, the lack of relevant baseline information for the frequency of drug-resistant tuberculosis (TB) gene mutations is a critical issue, and the incidence of this infection in the city of Changchun has not investigated to date. However, compared with the slow traditional methods of drug susceptibility testing, recently developed detection methods, such as rifampicin and isoniazid resistance-related gene chip techniques, allow for rapid, easy detection and simultaneous testing for mutation frequency and drug resistance.
\end{abstract}

Methods: In this study, the rifampicin and isoniazid resistance-related gene mutation chip method was employed for an epidemiological investigation. To assess the gene mutation characteristics of drug-resistant TB and evaluate the chip method, we tested 2143 clinical specimens from patients from the infectious diseases hospital of Changchun city from January to December 2016. The drug sensitivity test method was used as the reference standard.

Results: The following mutation frequencies of sites in the rifampicin resistance gene $r p o B$ were found: Ser531Leu (52.6\%), His526Tyr (12.3\%), and Leu511Pro (8.8\%). The multidrug-resistance (MDR)-TB mutation frequency was 34.7\% for rpoB Ser531 Leu and katG Ser315Thr, 26.4\% for rpoB Ser531Leu and inhA promoter - $15(C \rightarrow$ ), and 10.7\% for rpoB His526Tyr and katG Ser315Thr. In addition, drug susceptibility testing served as a reference standard. In previously treated clinical cases, the sensitivity and specificity of GeneChip were 83.1 and 98.7\% for rifampicin resistance, 79.9 and 99.6\% for isoniazid resistance, and 74.1 and $99.8 \%$ for MDR-TB.

Conclusions: Our experimental results show that the chip method is accurate and reliable; it can be used to detect the type of drug-resistant gene mutation in clinical specimens. Moreover, this study can be used as a reference for future research on TB resistance baselines.

Keywords: Mycobacterium tuberculosis, Drug resistance, Gene chip

\section{Background}

According to a survey from the World Health Organization (WHO) in 2015, an estimated 1.4 million people have died from tuberculosis (TB) [1]. Although TB deaths decreased by $22 \%$ from 2000 to 2015 , TB remained one of the top ten causes of death worldwide in 2015. In some areas, the proportion of multidrug-resistant (MDR)-TB in patients

\footnotetext{
* Correspondence: 582347027@qq.com; yuan_bao@jlu.edu.cn ${ }^{1}$ Department of Laboratory Animals, College of Animal Sciences, Jilin University, Changchun 130062, Jilin, China

Full list of author information is available at the end of the article
}

increased to a quarter of the $\mathrm{TB}$ cases on record. The WHO called for investing more funds for the treatment of MDR-TB to prevent the global spread of the disease. However, compared with conventional TB treatment, MDR-TB treatment is approximately 50 times to 200 times more expensive. Isoniazid (INH) and rifampicin (RFP) are the two most common first-line anti-TB drugs, but their widespread application has exacerbated resistance [2-4].

Because the traditional drug susceptibility testing (DST) method is time consuming and cumbersome, a TB drug sensitivity test with an improved Löwenstein-

(c) The Author(s). 2018 Open Access This article is distributed under the terms of the Creative Commons Attribution 4.0 International License (http://creativecommons.org/licenses/by/4.0/), which permits unrestricted use, distribution, and reproduction in any medium, provided you give appropriate credit to the original author(s) and the source, provide a link to the Creative Commons license, and indicate if changes were made. The Creative Commons Public Domain Dedication waiver (http://creativecommons.org/publicdomain/zero/1.0/) applies to the data made available in this article, unless otherwise stated. 
Jensen medium and BACTEC MGIT 960 liquid culture is currently being implemented. However, waiting three to 4 weeks for the results is required after obtaining isolates, even if the BACTEC MGIT 960 liquid culture method is quickly applied. Furthermore, after a susceptible culture is identified, an additional 9-13 days are needed to obtain results; thus, the requirements for rapid clinical diagnosis are not being met [5-7]. A number of molecular techniques have been successfully applied to Mycobacterium tuberculosis isolates, including real-time polymerase chain reaction (RT-PCR), line probe assays (LPAs) and oligonucleotide or DNA microarrays. Development of oligonucleotide or DNA microarrays has proven feasible and practical in $M$. tuberculosis research $[8,9]$. The CapitalBio ${ }^{\text {Tm }}$ DNA microarray method, which incorporates specific nucleotides at given positions of the rpoB, inhA and katG genes, has been developed to detect M. tuberculosis isolates and MDR forms in sputum specimens, with notable sensitivity and specificity. A previous study reported an accuracy of $91.8 \%$ for predicting RFP susceptibility and $70.2 \%$ for predicting isoniazid (INH) susceptibility compared with those of phenotypic DST, with detection in only $6 \mathrm{~h}[10,11]$. Among those genes assessed by the CapitalBio ${ }^{\text {Tw }}$ microarray, the following mutation sites in 13 isolates have been found in the RFP resistance-related gene rpoB: Ser531Leu (TCG $\rightarrow$ TTG), Ser531Trp (TCG $\rightarrow$ TGG), His526Asp (CAC $\rightarrow$ GAC), His526Tyr $(\mathrm{CAC} \rightarrow \mathrm{TAC})$, His526Leu $(\mathrm{CAC} \rightarrow$ CTC), His526Arg (CAC $\rightarrow$ CGC), Leu511Pro (CTG $\rightarrow$ CCG), Gln513Leu (CAA $\rightarrow$ CCA), Gln513Lys $(\mathrm{CAA} \rightarrow$ AAA), Asp516Val (GAC $\rightarrow$ GTC), Asp516Tyr $($ GAC $\rightarrow$ TAC), Asp516Gly (GAC $\rightarrow$ GGC) and Leu533Pro (CTG $\rightarrow$ CCG). In addition, two mutants, Ser315Thr $(\mathrm{AGC} \rightarrow \mathrm{ACC})$ and Ser315Asn (AGC $\rightarrow$ AAC), have been detected in the $k a t G$ gene, as well as the $-15(\mathrm{C} \rightarrow \mathrm{T})$ mutation in the inhA gene promoter [12] (Fig. 1).

\section{a}

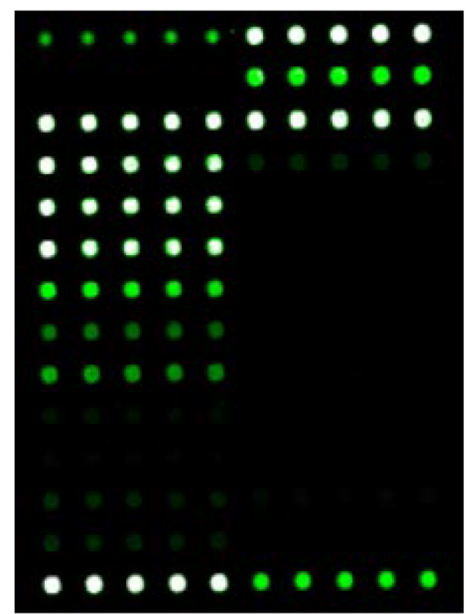

\begin{tabular}{|c|c|}
\hline $\mathrm{QC}$ & $\overline{\mathrm{EC}}$ \\
\hline$B C$ & rpoB IC \\
\hline Mycobacterium & Mycobacterium tuberculosis \\
\hline $511 \mathrm{WT}(\mathrm{CTG})$ & $511(\mathrm{CI} G \rightarrow C \underline{C} G)$ \\
\hline $513 \mathrm{WT}$ (CAA) & $513(\underline{C} A A \rightarrow \underline{A} A A)$ \\
\hline $516 \mathrm{WT}(\mathrm{GAC})$ & $513(\mathrm{CA} A \mathrm{~A} \rightarrow \mathrm{C} \underline{\mathrm{CA}} \mathrm{A})$ \\
\hline $533 \mathrm{WT}$ (CTG) & $533(\mathrm{C} \underline{\mathrm{C}} \rightarrow \mathrm{C} \underline{\mathrm{C}} \mathrm{G})$ \\
\hline $531 \mathrm{WT}(\mathrm{TCG})$ & $531(T \underline{G} G \rightarrow T I G)$ \\
\hline $526 \mathrm{WT}(\mathrm{CAC})$ & $531(\mathrm{~T} \underline{G} \rightarrow \mathrm{TGG})$ \\
\hline $526(\underline{\mathrm{C}} \mathrm{AC} \rightarrow \underline{\mathrm{TAC}})$ & $526(\underline{\mathrm{CAC}} \rightarrow \underline{\mathrm{G} A C})$ \\
\hline $526($ CA $\underline{C} \rightarrow C \underline{C} \mathrm{C})$ & $526(C \underline{A} \mathrm{C} \rightarrow \mathrm{C} \underline{\mathrm{G}} \mathrm{C})$ \\
\hline $516(\mathrm{GAC} \rightarrow \mathrm{G} \underline{\mathrm{IC}})$ & $516(\underline{G} A C \rightarrow \underline{I A C})$ \\
\hline $516(\mathrm{GAC} \rightarrow \mathrm{G} \underline{\mathrm{G}} \mathrm{C})$ & $\mathrm{NC}$ \\
\hline$\overline{\mathrm{EC}}$ & $\mathrm{QC}$ \\
\hline
\end{tabular}

b

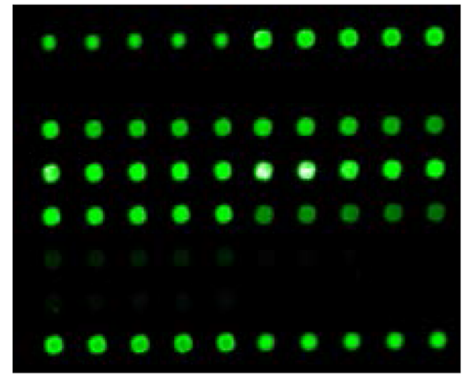

\begin{tabular}{|c|c|}
\hline $\mathrm{QC}$ & $\mathrm{EC}$ \\
\hline $\mathrm{BC}$ & $\mathrm{BC}$ \\
\hline Mycobacterium & Mycobacterium tuberculosis \\
\hline$k a t \mathrm{G}$ IC & $i n h \mathrm{~A}$ IC \\
\hline$k a t \mathrm{G} 315 \mathrm{WT}(\mathrm{AGC})$ & $i n h \mathrm{~A}-15 \mathrm{WT}(\mathrm{C})$ \\
\hline$k a t \mathrm{G} 315(\mathrm{~A} \underline{\mathrm{GC}} \rightarrow \mathrm{A} \underline{\mathrm{C}})$ & $i n h \mathrm{~A}-15(\mathrm{C} \rightarrow \mathrm{T})$ \\
\hline$k a t \mathrm{G} 315(\mathrm{~A} \underline{\mathrm{GC}} \rightarrow \mathrm{A} \underline{\mathrm{A} C})$ & $\mathrm{NC}$ \\
\hline $\mathrm{EC}$ & $\mathrm{QC}$ \\
\hline
\end{tabular}

Fig. 1 CapitalBio $^{\text {TM }}$ DNA microarray detection site layout. The contents of the table on the right side correspond to the microarray hybridization dot matrix on the left side in each figure. Every five repeated hybrid grid points correspond to one cell of specific content. QC: surface chemical quality control probe; EC: external control probe for hybridization-based quantitation; BC: blank control; NC: negative control probe; IC: internal control probe for PCR; WT: wild-type. a: Six sites detected in the rpoB gene, Ser531Leu (TCG $\rightarrow$ TTG), Ser531Trp (TCG $\rightarrow$ TGG), His526Asp (CAC $\rightarrow$ GAC), His526Tyr (CAC $\rightarrow$ TAC), His526Leu (CAC $\rightarrow$ CTC), His526Arg (CAC $\rightarrow$ CGC), Leu511Pro (CTG $\rightarrow$ CCG), Gln513Leu (CAA $\rightarrow$ CCA), Gln513Lys (CAA $\rightarrow$ AAA), Asp516Val (GAC $\rightarrow$ GTC), Asp516Tyr (GAC $\rightarrow$ TAC), Asp516Gly (GAC $\rightarrow$ GGC) and Leu533Pro (CTG $\rightarrow$ CCG), for a total of 13 types of mutants. b: The katG gene and a locus of the inhA gene promoter were tested as isoniazid resistance-related genes. The contents of the table on the right side correspond to the microarray hybridization dot matrix on the left side in each figure. Two katG gene mutants, Ser315Thr (AGC $\rightarrow$ ACC) and Ser315Asn (AGC $\rightarrow$ AAC), and one inhA gene promoter mutant, $-15(C \rightarrow T)$ mutant, were identified 
In 2007, a national survey of drug-resistant $\mathrm{TB}$ was carried out in China but covered only 10 of 31 provinces, and Jilin Province was not included [13]. The city of Changchun is the capital of Jilin Province, and as a representative city of northeast China, it has a dense population and a large population flow. As the number of patients with TB is rising each year, assessing MDRTB has become the main task of the current TB prevention and control program in the region. However, the city of Changchun has not yet been included in the TB drug-resistance statistics. Managing outbreaks of TB and studying epidemiological characteristics and resistance for the prevention and control of drug-resistant TB is of great significance for previously treated tuberculosis. At the same time, given that the two first-line drugs, namely, INH and RFP, are associated with resistance, the incidence of resistant TB is increasing and comprises a large proportion of the total cases [14]. In this study, previously treated tuberculosis patients in Changchun Infectious Disease Hospital were analyzed from January to December 2016. We used the CapitalBio ${ }^{\mathrm{T}}$ DNA microarray method and the DST approach as the reference standard to assess these cases in Changchun for rроB and inh $A$ mutations. We examined the molecular characteristics of kat $G$ gene mutation and correlations with INH and RFP resistance mutations with many clinical samples. Our results have important guiding value for clinical diagnosis and evaluation of developing trends in $\mathrm{TB}$ resistance.

This report is the first to describe a microarray analysis of mutations in the rpoB, katG and inhA genes of $M$. tuberculosis in a large number of clinical isolates in northeast China.

\section{Methods}

\section{Clinical specimens}

Patients with infectious diseases in the hospital of Changchun were included in this study. This hospital is the only designated tuberculosis hospital in Changchun; the number of outpatients was 71,139 from January to December 2016, and the number of hospitalized patients was 8890 . Patients were assessed using the WHO Treatment of Tuberculosis: Guidelines [15]. This investigation was a retrospective study conducted from January 2016 to December 2016. Among the 9612 specimens screened, only those from patients with previously treated tuberculosis were included. In total, 2143 sputum samples were obtained for evaluation by DST and CapitalBio ${ }^{\mathrm{ma}}$ DNA microarray testing (Additional file 1). A total of 1409 cultures were negative, whereas 3 cultures were contaminated with other microbes. Sixteen cultures contained non-TB mycobacteria, and the DST results for 3 specimens were invalid. Of the specimens used for the Capital$\mathrm{Bio}^{\mathrm{Tx}}$ DNA microarray test, 1411 were negative, or the amount of TB bacteria did not meet the minimum testing standards for $M$. tuberculosis. Eighteen specimens were identified as non-TB mycobacteria, 8 specimens were contaminated, and the results for 10 specimens were invalid. The results for 712 specimens were valid for DST evaluation. The results for 696 specimens were valid for GeneChip evaluation. In summary, the results of two tests revealed that 671 specimens were usable for evaluation of the performance of GeneChip. (Fig. 2).

\section{Culture and DST}

DST was performed using Löwenstein-Jensen medium. The specimens were processed according to standard WHO procedures. The following critical concentrations were used: $0.2 \mu \mathrm{g} / \mathrm{ml}$ for INH and $40.0 \mu \mathrm{g} / \mathrm{ml}$ for RFP [16]. Staff members of all laboratories were trained and approved by the National Reference Laboratory of Tuberculosis.

\section{CapitalBio $^{\mathrm{TM}}$ DNA microarray testing}

For sputum sample collection and processing, the first sputum sample was collected in the early morning. After a clear water gargle, we first asked the patient to produce a deep, hard cough to raise sputum; the sample was deposited in sterile sample containers, sealed, and inspected. The samples were incubated 1 to 2 times in $4 \% \mathrm{NaOH}$, with agitation. After 15 to 20 min, we added mixed phosphate

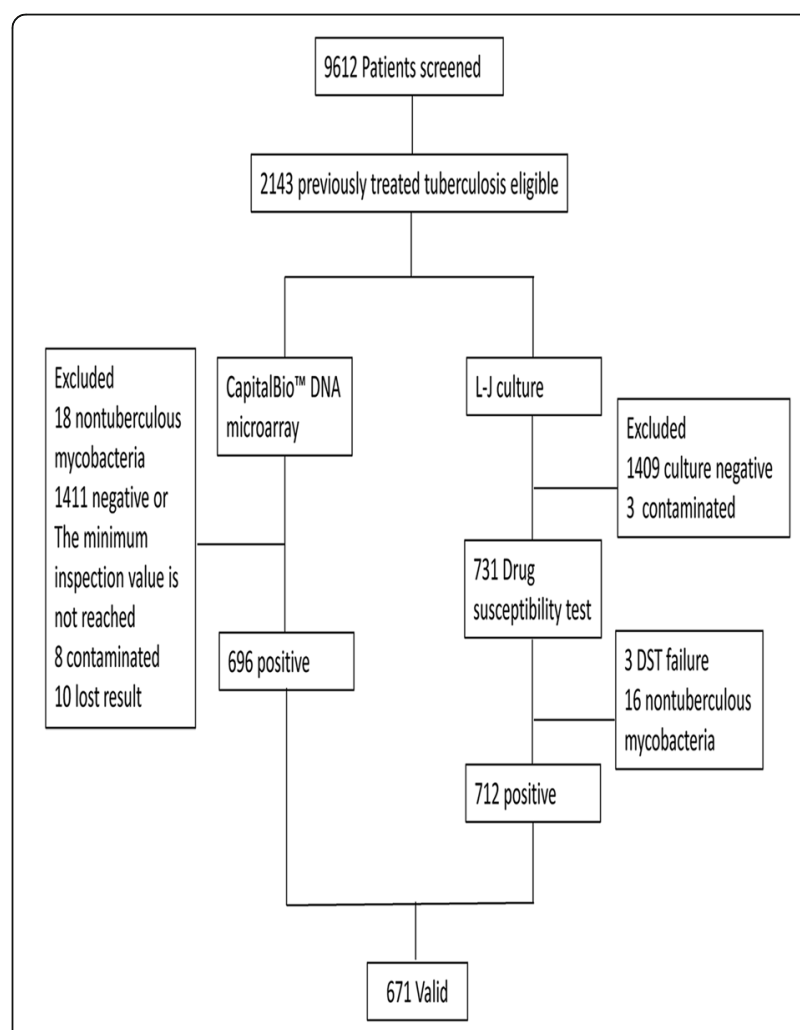

Fig. 2 Study profile: Flow chart of tuberculosis subjects included in this study. Summary of the results of the two tests for 671 specimens 
buffer, $\mathrm{pH}$ 6.8. After centrifugation, the supernatant was precipitated, and the pellet was washed with 0 . 5-1 $\mathrm{ml}$ of mixed phosphate buffer. The precipitates were then applied to the GeneChip according to the manufacturer's instructions. The results were obtained via semi-automatic scanning using a LuxScan 10 K.B microarray scanner (CapitalBio Technology Inc., Beijing, China) (see Fig. 3 for common results).

\section{Statistical analyses}

For data analysis, DST results were used as the reference standard to calculate the sensitivity, specificity, positive predictive value (PPV), and negative predictive value (NPV) of the CapitalBio ${ }^{\mathrm{Tm}}$ DNA microarray. A chi-squared test was used for statistical analysis, and the criterion for significance was set at a $P$ value of 0.05 based on a two-sided test. All statistics were performed with SPSS 17.0 software (Statistical Package for the Social Sciences, Inc., Chicago, IL, USA).

\section{Results}

\section{CapitalBio $^{\mathrm{TM}}$ DNA microarray test and DST results}

The CapitalBio ${ }^{\text {тм }}$ DNA microarray test was employed for 671 samples, including 437 wild-type samples, 57 with RFP resistance, 56 with INH resistance, and 121 with RFP and INH resistance. In addition, 671 samples were analyzed by DST, including 407 wild-type samples, 45 with RFP resistance, 57 with INH resistance, and 162 with RFP and INH resistance.
Performance evaluation of the CapitalBio ${ }^{\mathrm{TM}}$ DNA microarray test for RFP and INH resistance among TB cases

The overall sensitivity, specificity, agreement rate, PPV, NPV, and kappa values were 83.1, 98.7, 93.9, 96.6, 92.9\% and 0.85 , respectively, for detection of $M$. tuberculosis RFP resistance. With regard to $M$. tuberculosis INH resistance, the overall sensitivity, specificity, agreement rate, PPV, NPV, and kappa values were 79.9, 99.6, 93.1, 98.8, 91.1\% and 0.84 , respectively (Table 1 ).

For detecting $M$. tuberculosis MDR, the overall sensitivity, specificity, agreement rate, PPV, NPV, and kappa values were $74.1,99.8,93.6,99.2,92.4 \%$ and 0.81 , respectively (Table 2).

\section{Rifampicin resistance-related gene mutations in $r p o B$}

Among the 57 cases with RFP resistance, the following mutations were found: 30 cases with Ser531Leu (52.6\%), 7 cases with His526Tyr (12.3\%), 2 cases with His526Leu (3.5\%), 5 cases with Leu511Pro (8.8\%), 1 case with Gln513Lys (1.8\%), 2 cases with Asp516Val (3.5\%), 3 cases with Asp516Tyr (5.3\%), 2 cases with Asp516Gly (3.5\%), 3 cases with Leu533Pro (5.3\%), 1 case with Asp516TyrGln513LeuLeu511Pro (1.8\%), and 1 case with Ser531LeuLeu511Pro (1.8\%) (Table 3).

Isoniazid resistance-related gene mutations in katG and inhA Among the 56 cases with INH resistance, 30 cases had the katG 315 AGC $\rightarrow$ ACC mutation (53.6\%), and 26 cases had the $i n h A-15(C \rightarrow T)$ mutation (46.4\%) (Table 4). a

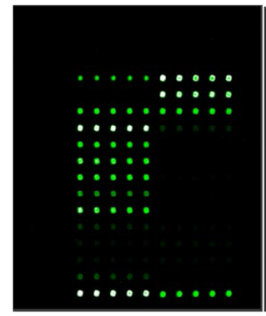

b

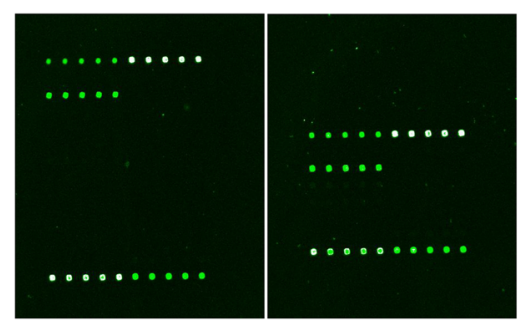

C

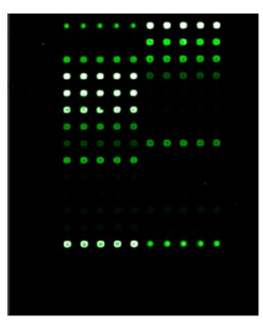

e

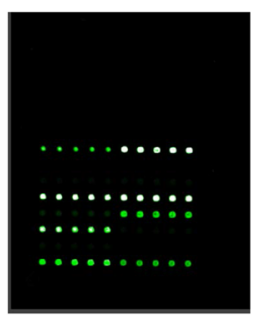

d

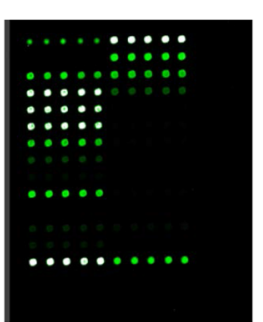

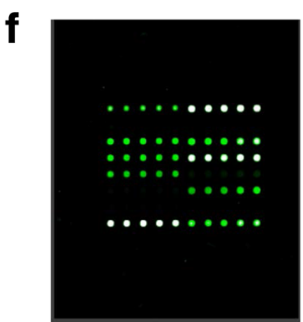

Fig. 3 Common results of the CapitalBio ${ }^{T M}$ DNA microarray detection spectra are shown for samples with mutation(s) at a: WT: wild-type. b: NTB: nontuberculous mycobacteria. c: rpoB gene codon 531 (TCG $\rightarrow$ TTG). d: rpoB gene codon 526 (CAC $\rightarrow$ TAC). e: katG gene codon 315 (AGC $\rightarrow$ ACC). f: inhA gene promoter $-15(\mathrm{C} \rightarrow \mathrm{T})$ 
Table 1 Performance evaluation of the CapitalBio ${ }^{\text {TM }}$ DNA microarray for rifampin and isoniazid resistance in tuberculosis cases compared with the standard drug sensitivity testing (DST) method for the 671 samples

\begin{tabular}{|c|c|c|c|c|c|c|c|c|c|}
\hline \multirow{2}{*}{$\begin{array}{l}\text { CapitalBio }^{\mathrm{TM}} \\
\text { DNA } \\
\text { microarray } \\
\end{array}$} & \multicolumn{2}{|c|}{ Conventional drug susceptibility testing } & \multirow[b]{2}{*}{ Total No. } & \multirow[b]{2}{*}{ Sensitivity (\%) } & \multirow[b]{2}{*}{ Specificity (\%) } & \multirow[b]{2}{*}{$A R$} & \multirow[b]{2}{*}{ PPV (\%) } & \multirow[b]{2}{*}{ NPV (\%) } & \multirow[b]{2}{*}{ Kappa } \\
\hline & No.susceptible (\%) & No.resistant (\%) & & & & & & & \\
\hline Rifampin & & & & 83.1 & 98.7 & 93.9 & 96.6 & 92.9 & 0.85 \\
\hline Susceptible & $458(98.7)$ & $35(16.9)$ & 493 & & & & & & \\
\hline Resistant & $6(1.3)$ & $172(83.1)$ & 178 & & & & & & \\
\hline Total & 464 & 207 & 671 & & & & & & \\
\hline Isoniazid & & & & 79.9 & 99.6 & 93.1 & 98.8 & 91.1 & 0.84 \\
\hline Susceptible & $450(99.3)$ & $44(20.5)$ & 494 & & & & & & \\
\hline Resistant & $2(0.7)$ & $175(79.5)$ & 177 & & & & & & \\
\hline Total & 452 & 219 & 671 & & & & & & \\
\hline
\end{tabular}

Abbreviations: PPV positive predictive value, NPV negative predictive value, AR agreement rate

Rifampicin and isoniazid resistance-related gene mutations in rpoB, katG and inhA

Among the 121 MDR-TB samples, 42 (34.7\%) showed rpoB Ser531L and katG S315 T, 32 (26.4\%) rpoB Ser531L and $i n h A$ promoter $-15(\mathrm{C} \rightarrow \mathrm{T})$, and $13(10.7 \%)$ rрoB His526Tyr and katG Ser315Thr (Table 5).

\section{Discussion}

\section{Evaluation of the DNA microarray method}

TB infection is a serious health problem that threatens the health of people worldwide and creates a serious medical burden. TB detection methods primarily include sputum smear acid fast staining, DST methods and DNA microarray techniques. Popular in recent years, the DNA microarray method is a rapid detection approach. Indeed, chip methods are more rapid and accurate than culture and DST [17]. These techniques have the potential to guide the use of medication. Compared with culture and DST results, which are obtained in 6 weeks, DNA microarray results are obtained in 6 hours $[11,18]$. In our study, we performed an evaluation using a large number of clinical samples and the DST method as a reference standard. High consistency was observed for the DNA microarray and DST methods. The overall sensitivity, specificity, agreement rate, PPV, NPV, and kappa values were 83.1, 98.7, 93.9, 96.6, 92.9\% and 0.85 for detecting M. tuberculosis RFP resistance, respectively; 79.9, 99.6, 93.1, 98.8, 91.1\% and 0.84 for detecting $M$. tuberculosis INH resistance, respectively; and 74.1, 99.8, 93.6, 99.2, 92.4\% and 0.81 for detecting MDR$\mathrm{TB}$, respectively. These results were consistent with those reported by Guo, Y. et al., Pang, Y. et al., Tang, P et al., and Zhu, L. et al. [10, 19-21]. However, compared with the MeltPro TB assay method in detection of TB drug resistance $[22,23]$. our chip method is less sensitive and has higher specificity.

\section{Limitations of the DNA microarray method}

Based on the data shown in Table 1, RFP and INH mono-resistance positivity rates were $26.5 \%(178 / 671)$ and $26.4 \%(177 / 671)$, respectively, according to the DNA microarray method; these rates were slightly lower than the DST results at 30.8\% (207/671) and 32 . $6 \%$ (219/671), respectively. The sensitivity values for RFP and INH were 83.1 and $79.9 \%$, respectively, and the potential cause of this result is that some mutations occur beyond the limits of the chip testing sites. In some previous studies, the drug INH up-regulated the phenotypes of genes, such as $\operatorname{ahpC}, k a s A, N D H$, ini $A B C$, fadE, and furA; thus, these gene phenotypes should be included in the detection range [2, 24, 25]. This phenomenon also led to further widening of the detection gap between the two methods; the positive rate for the chip method was $18.0 \%$ (121/671), whereas

Table 2 Performance evaluation of the CapitalBio ${ }^{\text {TM }}$ DNA microarray for MDR-TB cases compared with the standard drug sensitivity testing (DST) method for the 671 samples

\begin{tabular}{|c|c|c|c|c|c|c|c|c|c|}
\hline \multirow[b]{2}{*}{ CapitalBio $^{\mathrm{TM}}$ DNA microarray } & \multicolumn{2}{|c|}{ Conventional drug susceptibility testing } & \multirow[b]{2}{*}{ Total No. } & \multirow[b]{2}{*}{ Sensitivity (\%) } & \multirow[b]{2}{*}{ Specificity (\%) } & \multirow[b]{2}{*}{$A R$} & \multirow[b]{2}{*}{ PPV (\%) } & \multirow[b]{2}{*}{ NPV (\%) } & \multirow[b]{2}{*}{ Kappa } \\
\hline & MDR-TB (\%) & non-MDR (\%) & & & & & & & \\
\hline & & & & 74.1 & 99.8 & 93.6 & 99.2 & 92.4 & 0.81 \\
\hline MDR-TB & $120(74.1)$ & $1(0.2)$ & 121 & & & & & & \\
\hline Non-MDR & $42(25.9)$ & 508 (99.8) & 550 & & & & & & \\
\hline total & 162 & 509 & 671 & & & & & & \\
\hline
\end{tabular}


Table 3 Microarray chip detection of mutations in Mycobacterium tuberculosis rpoB-RRDR relevant mutation sites for the 57 samples

\begin{tabular}{llll}
\hline Codon mutation & Nucleic acid change & No. of strains & Frequency (\%) \\
\hline Ser531Leu & TCG $\rightarrow$ TTG & 30 & 52.6 \\
His526Tyr & CAC $\rightarrow$ TAC & 7 & 12.3 \\
His526Leu & CAC $\rightarrow$ CTC & 2 & 3.5 \\
Leu511Pro & CTG $\rightarrow$ CCG & 5 & 8.8 \\
Asp516Val & GAC $\rightarrow$ GTC & 2 & 3.5 \\
Asp516Tyr & GAC $\rightarrow$ TAC & 3 & 5.3 \\
Asp516Gly & GAC $\rightarrow$ GGC & 2 & 3.5 \\
Gln513Lys & CAA $\rightarrow$ AAA & 1 & 1.8 \\
Leu533Pro & CTG $\rightarrow$ CCG & 3 & 5.3 \\
Ser531LeuLeu511Pro & TCG $\rightarrow$ TTG CTG $\rightarrow$ CCG & 1 & 1.8 \\
Asp516TyrGIn513LeuLeu511Pro & GAC $\rightarrow$ TAC CAA $\rightarrow$ CCA CTG $\rightarrow$ CCG & 1 & 1.8 \\
Total & & 57 & \\
\hline
\end{tabular}

that of traditional culture DST was $24.1 \%$ (162/671). Increasing the number of detection sites in the DNA microarray test and expanding its detection range may help to increase sensitivity. In addition, some samples may have primary (natural) resistance [26, 27], as opposed to resistance caused by genetic mutations. For such cases, the CapitalBio ${ }^{\mathrm{TM}}$ DNA microarray method may need to be improved.

Although the chip method has limitations, it is still suitable for TB epidemic areas due to its rapid and accurate characteristics. Indeed, results can be quickly obtained with this tool compared with the traditional detection method, which requires 3 months or more for results. Thus, patients with MDR-TB can be quickly treated with an appropriate second-line treatment, with better outcomes.

\section{Drug-resistance gene mutations}

rpoB gene mutation is the most important cause of RFP resistance. The main mutation in $r p o B$ was the Ser531Leu mutation, which occurred in our samples, followed by mutations of residue 526. In similar previous reports, the 531 mutation was the most commonly detected, followed by the 526 mutation [28-32]. The results of our experiment revealed strains with mutations at three loci that were resistant to RFP (i.e., rрoB Asp516Tyr plus Gln513Leu plus Leu511Pro).

Table 4 Mutations in katG and inhA gene in 56 rifampin-resistant M. tuberculosis isolates

\begin{tabular}{llll}
\hline Codon mutation & Nucleic acid change & No. of strains & Frequency (\%) \\
\hline katG & & & \\
Ser315Thr & AGC $\rightarrow$ ACC & 30 & 53.6 \\
inhA & & 26 & 46.4 \\
$C(-15) \rightarrow T$ & $C \rightarrow T$ & 56 & \\
Total & &
\end{tabular}

Previously, this finding was rarely reported, and we should be aware of this possibility in the future.

Table 4 shows that INH mutations primarily occur at $k a t G 315$ and in the $i n h A$ promoter at -15 . For katG 315 , AGC to ACC was the main mutation of this residue in our study, with $100 \%$ of cases showing the katG Ser315Thr AGC to ACC mutation, and we found no Ser315Asn AGC to AAC mutations, which was consistent with previous reports [21, 33]. However, in our study, inhA - 15 locus mutations accounted for $46.4 \%$ of all INH resistance mutations, which was inconsistent with previous reports [34-36]. Among the 56 cases of INH resistance mutations, 30 were katG 315 AGC $\rightarrow$ ACC (53.6\%), and 26 were $\operatorname{inh} A-15(\mathrm{C} \rightarrow \mathrm{T})(46.4 \%)$. Mutation rates of $14-17 \%$ and $22-24 \%$ have been reported for katG $315 \mathrm{AGC} \rightarrow \mathrm{ACC}$ and $i n h A-15(\mathrm{C} \rightarrow$ $\mathrm{T})$, respectively $[28,34]$; these values are very different from our results. This discrepancy may be caused by regional differences [2].

According to the results of our study, the resistance rates among the $671 \mathrm{M}$. tuberculosis strains with resistance were $26.5 \%(178 / 671), 26.4 \%$ (177/671) and $18.0 \%(121 / 671)$ for RFP mono-resistance, INH mono-resistance, and MDR, respectively. Our results were compared with a RFP resistance rate of $29.4 \%$, an $\mathrm{INH}$ resistance rate of $38.5 \%$, and a MDR rate of $25.6 \%$, according to the results reported by Guo, Y. et al. [13]. However, the positive rates of RFP, INH and MDR resistance have varying degrees of decline; the reason for this reduction may be an increase in the use of second-line drugs. Although the use of these drugs would reduce the drug resistance of $\mathrm{TB}$ to first-line drugs, an increase in resistance rates to second-line drugs may lead to an increase in the overall prevalence of drug resistance [37]. A more scientific drug regimen and drug-resistant $\mathrm{TB}$ control should be further investigated. 
Table 5 Microarray chip detection of rpoB-RRDR,KatG315 and inhA-15 mutation points for the 121 samples

\begin{tabular}{|c|c|c|c|c|}
\hline Codon mutation in rpoB & Codon mutation in katG & Codon mutation in inhA & No. of strains & Frequency (\%) \\
\hline Ser531Leu & Ser315Thr & & 42 & 34.7 \\
\hline Ser531Leu & & $C(-15) \rightarrow T$ & 32 & 26.4 \\
\hline Ser531Leu & Ser315Thr & $C(-15) \rightarrow \top$ & 2 & 1.7 \\
\hline Ser531LeuAsp516Tyr & & $C(-15) \rightarrow T$ & 2 & 1.7 \\
\hline Ser531LeuHis526Leu & & $C(-15) \rightarrow T$ & 1 & 0.8 \\
\hline His526Tyr & Ser315Thr & & 13 & 10.7 \\
\hline His526Tyr & & $C(-15) \rightarrow T$ & 4 & 3.3 \\
\hline His526Leu & Ser315Thr & & 2 & 1.7 \\
\hline His526Asp & Ser315Thr & & 2 & 1.7 \\
\hline His526AspGIn513Lys & Ser315Thr & & 1 & 0.8 \\
\hline His526Arg & Ser315Thr & & 1 & 0.8 \\
\hline Asp516Val & Ser315Thr & & 2 & 1.7 \\
\hline Asp516Tyr & Ser315Thr & & 2 & 1.7 \\
\hline Asp516Gly & Ser315Thr & & 1 & 0.8 \\
\hline Asp516ValLeu511Pro & & $C(-15) \rightarrow \top$ & 1 & 0.8 \\
\hline Asp516TyrLeu511Pro & & $C(-15) \rightarrow T$ & 1 & 0.8 \\
\hline Leu511Pro & & $C(-15) \rightarrow T$ & 2 & 1.7 \\
\hline Leu511Pro & Ser315Thr & & 2 & 1.7 \\
\hline Leu511ProAsp516Gly & Ser315Thr & & 2 & 1.7 \\
\hline Leu533Pro & & $C(-15) \rightarrow T$ & 2 & 1.7 \\
\hline Leu533Pro & Ser315Thr & & 2 & 1.7 \\
\hline Leu533Pro & Ser315Thr & $C(-15) \rightarrow \top$ & 1 & 0.8 \\
\hline Gln513Lys & Ser315Thr & & 1 & 0.8 \\
\hline Total & & & 121 & \\
\hline
\end{tabular}

\section{Conclusion}

Changchun is a provincial capital city of northeast China, and the data reported herein are representative of this region. We conducted statistical analysis of sputum samples from hospitalized TB patients from January 2016 to December 2016 in the Changchun Infectious Disease Hospital. In recent years, there have been few reports of epidemiological investigations of $\mathrm{TB}$ resistance in China, and advances in detection techniques may lead to higher detection rates and more accurate results. Our results indicate that the DNA microarray method is a rapid, accurate, practical approach with promise for auxiliary clinical drug-resistant $\mathrm{TB}$ diagnosis. Investigating mutations in drug-resistance genes is important for the effective treatment of drug-resistant TB. To improve TB drugresistance mutation detection, we should establish and improve an observation system and establish a new round of baseline investigation reports. Adopting the CapitalBio $^{\mathrm{Tm}}$ DNA microarray test to evaluate resistance will likely play a key role in this process.

\section{Additional file}

Additional file 1: Raw data of 2143 simples. Clinical specimens test results from the infectious diseases hospital of Changchun city from January to December 2016. (XLSX 65 kb)

Funding

This study was supported by the Key Technology R\&D Program (grant numbers 2015BAI07B02 and 20170623032TC).

Availability of data and materials

All data generated or analyzed during this study are included in this published article.

Authors' contributions

WZR, WG and BY were responsible for the main conception and design of the study; MJZ, XJS, YL, KWL and ZHJ performed the experiments; MJZ, WZR, XJS, YL, KWL, WG, BY analyzed the data and contributed reagents; MJZ, ZHJ, WG and BY wrote the manuscript; and all of the authors approved the final version.

\section{Ethics approval and consent to participate}

The study was approved by the Ethical Committee of Changchun Infectious Disease Hospital (approval number 2017001). The need for informed consent was deemed unnecessary by the committee according to national regulations. No patient-identifying data were collected. 


\section{Competing interests}

The authors declare that they have no competing interests.

\section{Publisher's Note}

Springer Nature remains neutral with regard to jurisdictional claims in published maps and institutional affiliations.

\section{Author details}

${ }^{1}$ Department of Laboratory Animals, College of Animal Sciences, Jilin University, Changchun 130062, Jilin, China. ${ }^{2}$ Department of Infectious Diseases, Changchun Infectious Hospital, Changchun 130123, Jilin, China.

Received: 3 February 2018 Accepted: 4 May 2018

Published online: 22 May 2018

\section{References}

1. WHO. Global tuberculosis report. Geneva: WHO; 2015

2. Unissa AN, Subbian S, Hanna LE, Selvakumar N. Overview on mechanisms of isoniazid action and resistance in Mycobacterium tuberculosis. Infect Genet Evol. 2016:45:474-92

3. Campbell EA, Korzheva N, Mustaev A, Murakami K, Nair S, Goldfarb A, et al Structural mechanism for rifampicin inhibition of bacterial rna polymerase. Cell. 2001;104:901-12.

4. Blanchard JS. Molecular mechanisms of drug resistance in Mycobacterium tuberculosis. Annu Rev Biochem. 1996;65:215-39.

5. Espasa M, Salvado M, Vicente E, Tudo G, Alcaide F, Coll P, et al. Evaluation of the VersaTREK system compared to the Bactec MGIT 960 system for first-line drug susceptibility testing of Mycobacterium tuberculosis. J Clin Microbiol. 2012:50:488-91.

6. Torelli Carpi P, Tortoli E. Results of different methods used for drug susceptibility of mycobacteria. Quad Sclavo Diagn. 1979;15(Suppl 1):580-5.

7. Kim SJ. Drug-susceptibility testing in tuberculosis: methods and reliability of results. Eur Respir J. 2005:25:564-9.

8. Saravanan M, Niguse S, Abdulkader M, Tsegay E, Hailekiros H, Gebrekidan A, et al. Review on emergence of drug-resistant tuberculosis (MDR \& XDR-TB) and its molecular diagnosis in Ethiopia. Microb Pathog. 2018;117:237-42.

9. Wang JP, Rought SE, Corbeil J, Guiney DG. Gene expression profiling detects patterns of human macrophage responses following Mycobacterium tuberculosis infection. FEMS Immunol Med Microbiol. 2003:39:163-72.

10. Guo Y, Zhou Y, Wang C, Zhu L, Wang S, Li Q, et al. Rapid, accurate determination of multidrug resistance in M. Tuberculosis isolates and sputum using a biochip system. Int J Tuberc Lung Dis. 2009;13:914-20.

11. Bumgarner R. Overview of DNA microarrays: types, applications, and their future. Curr Protoc Mol Biol. 2013; Chapter 22: Unit;22:1

12. Timmins GS, Deretic V. Mechanisms of action of isoniazid. Mol Microbiol. 2006:62:1220-7.

13. Zhao Y, Xu S, Wang L, Chin DP, Wang S, Jiang G, et al. National survey of drug-resistant tuberculosis in China. N Engl J Med. 2012:366:2161-70.

14. Sampathkumar $P$. Drug resistant tuberculosis: a global public health issue. Int J Dermatol. 2008:47:985-8

15. WHO/HTM/TB/2009.420. Guidelines for treatment of tuberculosis. fourth ed. Geneva: WHO; 2009

16. Barrera L, Cooreman E, de Dieu Iragena J, Drobniewski F, Duda P, Havelkova $M$, et al. Policy guidance on drug-susceptibility testing (DST) of second-line Antituberculosis drugs. Geneva: World Health Organization; 2008.

17. Markelov ML, Shipulin GA, Pokrovskii VI. Biochip technologies-new prospects in diagnosis of human diseases. Ter Arkh. 2008:80:79-85.

18. Pang Y, Li Q, Ou X, Sohn H, Zhang Z, Li J, et al. Cost-effectiveness comparison of Genechip and conventional drug susceptibility test for detecting multidrugresistant tuberculosis in China. PLoS One. 2013;8:e69267.

19. Zhu L, Liu Q, Martinez L, Shi J, Chen C, Shao Y, et al. Diagnostic value of GeneChip for detection of resistant Mycobacterium tuberculosis in patients with differing treatment histories. J Clin Microbiol. 2015:53:131-5.

20. Pang $Y$, Xia H, Zhang Z, Li J, Dong Y, Li Q, et al. Multicenter evaluation of genechip for detection of multidrug-resistant Mycobacterium tuberculosis. $J$ Clin Microbiol. 2013:51:1707-13.

21. Tang $P$, Wang $X$, Shen $X$, Shi M, Zhu X, Yu X, et al. Use of DNA microarray chips for the rapid detection of Mycobacterium tuberculosis resistance to rifampicin and isoniazid. Exp Ther Med. 2017;13:2332-8.

22. Pang $Y$, Dong $H$, Tan $Y$, Deng $Y$, Cai $X$, Jing $H$, et al. Rapid diagnosis of $M D R$ and XDR tuberculosis with the MeltPro TB assay in China. Sci Rep. 2016;6:25330.
23. Zhang T, Hu S, Li G, Li H, Liu X, Niu J, et al. Evaluation of the MeltPro TB/STR assay for rapid detection of streptomycin resistance in Mycobacterium tuberculosis. Tuberc (Edinb). 2015;95:162-9.

24. Chen $X, M a Y$, Jin Q, Jiang GL, Li CY, Wang Q. Characterization of the katG, inhA, ahpC, kasA, and oxyR gene mutations in isoniazid-resistant and susceptible strain of Mycobacterium tuberculosis by automated DNA sequencing. Zhonghua Jie He He Hu Xi Za Zhi. 2005;28:250-3.

25. Fu LM. Exploring drug action on Mycobacterium tuberculosis using affymetrix oligonucleotide genechips. Tuberc (Edinb). 2006:86:134-43.

26. De Rossi E, Ainsa JA, Riccardi G. Role of mycobacterial efflux transporters in drug resistance: an unresolved question. FEMS Microbiol Rev. 2006:30:36-52

27. De La Iglesia Al, Morbidoni HR. Mechanisms of action of and resistance to rifampicin and isoniazid in Mycobacterium tuberculosis: new information on old friends. Rev Argent Microbiol. 2006;38:97-109.

28. Desikan P, Kharate A, Panwalkar N, Khurana J, Mirza SB, Chaturvedi A, et al. Frequency of mutations in rifampicin and isoniazid resistant isolates of $\mathrm{M}$. Tuberculosis: an analysis from Central India. Germs. 2016;6:125-31.

29. Huang $H$, Jin Q, Ma Y, Chen X, Zhuang Y. Characterization of rpoB mutations in rifampicin-resistant Mycobacterium tuberculosis isolated in China. Tuberc (Edinb). 2002:82:79-83.

30. Makadia JS, Jain A, Patra SK, Sherwal BL, Khanna A. Emerging trend of mutation profile of rpoB gene in MDR tuberculosis, North India. Indian J Clin Biochem. 2012;27:370-4

31. Isakova Zh T. Distribution of mutations in the rpoB, katG, inhA, ahpC gene of rifampicin and isoniazid resistant M. Tuberculosis strains isolated in Kyrgyz Republic. Mol Gen Mikrobiol Virusol. 2008:4:36-8.

32. Zhang Z, Li L, Luo F, Cheng P, Wu F, Wu Z, et al. Rapid and accurate detection of RMP- and INH- resistant Mycobacterium tuberculosis in spinal tuberculosis specimens by CapitalBio DNA microarray: a prospective validation study. BMC Infect Dis. 2012;12:303.

33. Llerena C, Medina R. Description of Mycobacterium tuberculosis mutations conferring resistance to rifampicin and isoniazid detected by GenoType(R) MTBDRplus V.2 in Colombia. Biomedica. 2017:37:28-33.

34. Yao C, Zhu T, Li Y, Zhang L, Zhang B, Huang J, et al. Detection of rpoB, katG and inhA gene mutations in Mycobacterium tuberculosis clinical isolates from Chongqing as determined by microarray. Clin Microbiol Infect. 2010; 16:1639-43.

35. Monteserin J, Paul R, Latini C, Simboli N, Yokobori N, Delfederico L, et al. Relation of Mycobacterium tuberculosis mutations at katG315 and inhA-15 with drug resistance profile, genetic background, and clustering in Argentina. Diagn Microbiol Infect Dis. 2017;89:197-201.

36. Cafe Oliveira LN, Muniz-Sobrinho Jda S, Viana-Magno LA, Oliveira Melo SC, Macho A, Rios-Santos F. Detection of multidrug-resistant Mycobacterium tuberculosis strains isolated in Brazil using a multimarker genetic assay for katG and rpoB genes. Braz J Infect Dis. 2016;20:166-72.

37. WHO. Global tuberculosis report. Geneva: WHO; 2017.

\section{Ready to submit your research? Choose BMC and benefit from:}

- fast, convenient online submission

- thorough peer review by experienced researchers in your field

- rapid publication on acceptance

- support for research data, including large and complex data types

- gold Open Access which fosters wider collaboration and increased citations

- maximum visibility for your research: over $100 \mathrm{M}$ website views per year

\section{At BMC, research is always in progress.}

Learn more biomedcentral.com/submissions 